\title{
Supplement to "Bayesian Joint Modeling of Multiple Gene Networks and Diverse Genomic Data to Identify Target Genes of a Transcription Factor"
}

\author{
Peng Wei \& Wei Pan
}

1 WinBUGS code for implementing the SMJM with a general covariance structure

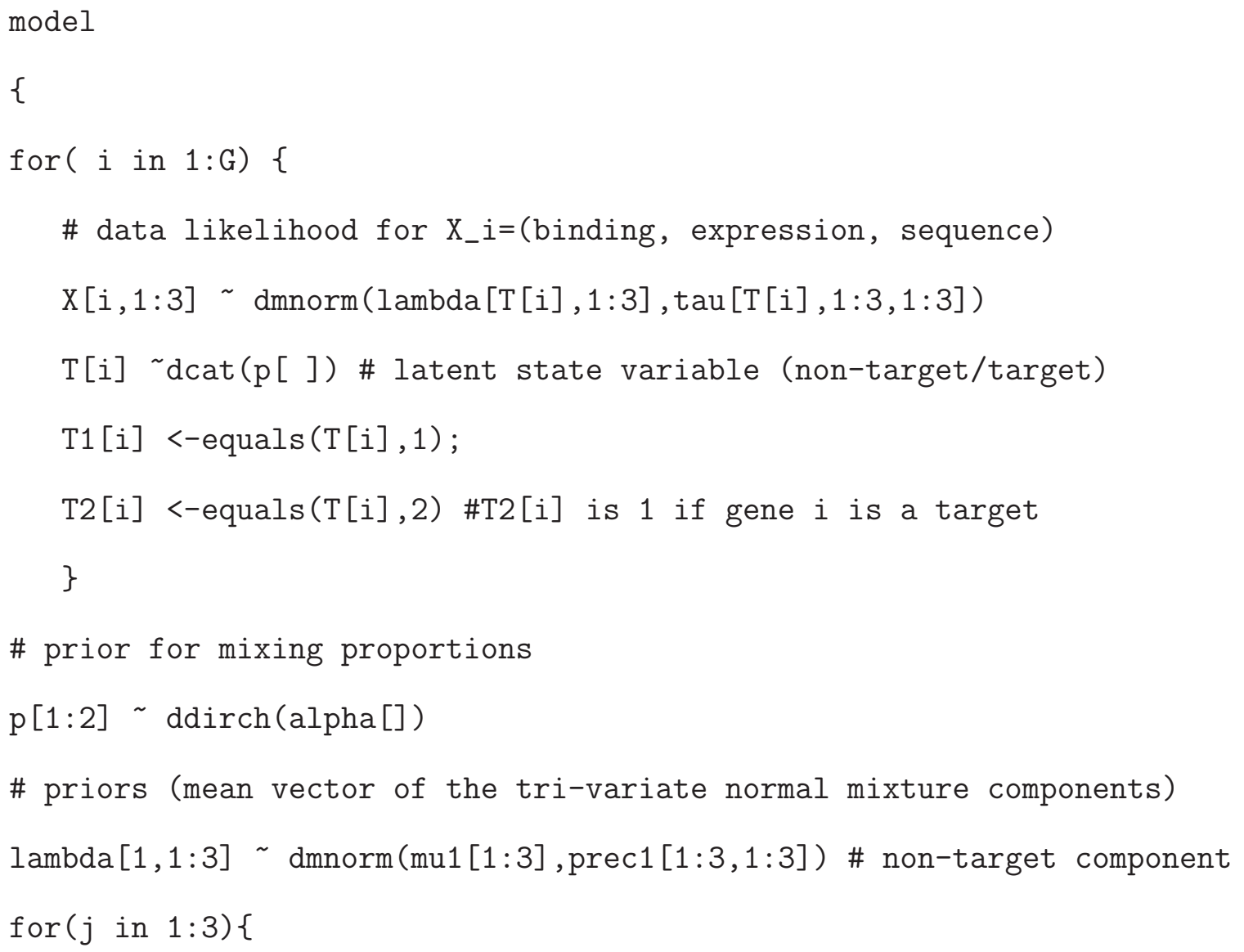




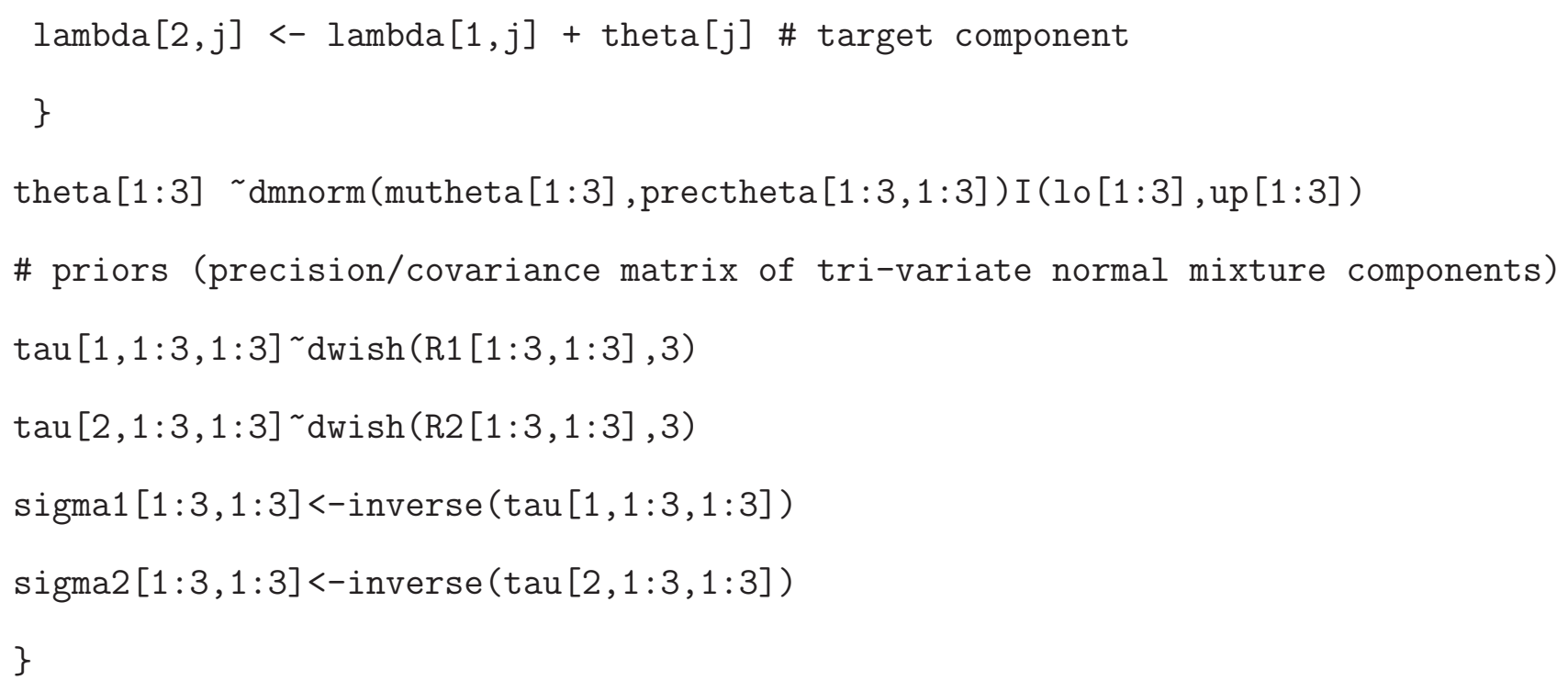

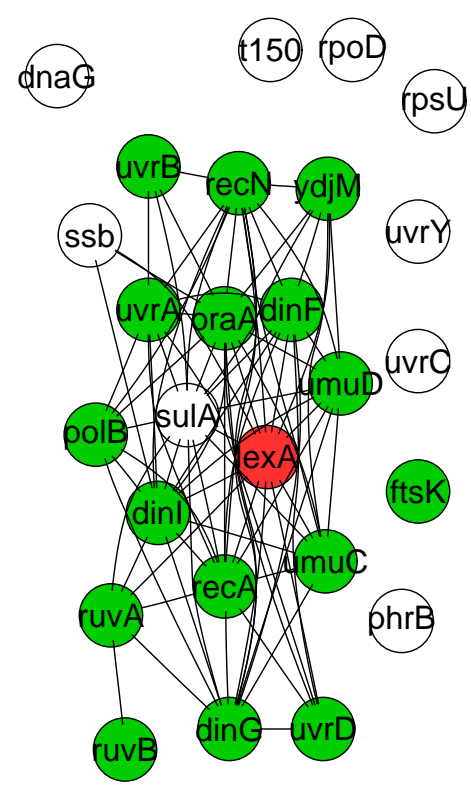

8 singletons, 83 edges

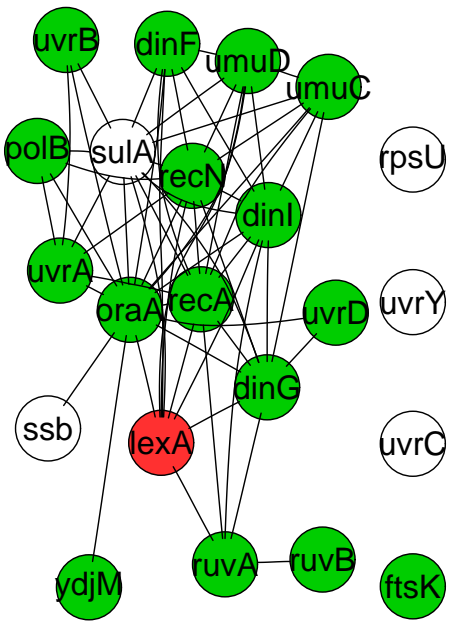

8 singletons, 61 edges

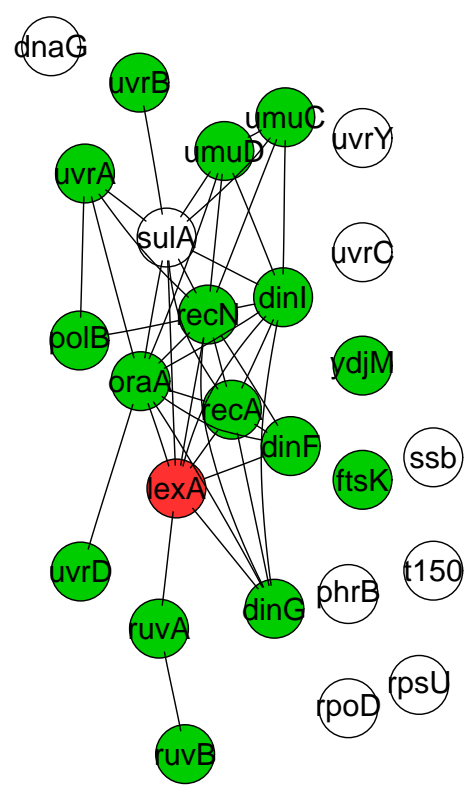

10 singletons, 41 edges

Figure 1: Subnetworks of LexA's known (colored/shaded nodes) and putative (blank nodes) target genes from co-expression networks with Pearson correlation coefficient cutoffs (a) 0.60, (b) 0.65, and (c) 0.70 . 
Table 1: Sensitivity analysis of the co-expression network. Ranks given by various methods based on posterior probabilities for known (marked by ${ }^{*}$ ) and putative target genes of LexA annotated in RegulonDB. "SMM":standard mixture model; "SMJM" :standard mixture joint model with diagonal covariance; "co-exp" :coexpression network; .60, .65 and .70 correspond to different cutoffs for the coexpression network.

\begin{tabular}{|c|c|c|c|c|c|c|c|c|}
\hline \multirow[t]{3}{*}{ Targets } & \multicolumn{4}{|c|}{ Expression } & \multicolumn{4}{|c|}{ Binding+Expression+Sequence } \\
\hline & \multirow[t]{2}{*}{ SMM } & \multicolumn{3}{|c|}{ MRF-MJM (co-exp) } & \multirow[t]{2}{*}{ SMJM } & \multicolumn{3}{|c|}{ MRF-MJM (co-exp) } \\
\hline & & .60 & .65 & .70 & & .60 & .65 & .70 \\
\hline umuD* & 1 & 1 & 1 & 1 & 1 & 1 & 1 & 1 \\
\hline recN* & 1 & 1 & 1 & 1 & 1 & 1 & 1 & 1 \\
\hline recA* & 1 & 1 & 1 & 1 & 1 & 1 & 1 & 1 \\
\hline lexA* & 1 & 1 & 1 & 1 & 1 & 1 & 1 & 1 \\
\hline dinI* & 1 & 1 & 1 & 1 & 1 & 1 & 1 & 1 \\
\hline ydjM* & 1 & 1 & 1 & 1 & 1 & 1 & 1 & 1 \\
\hline oraA* & 1 & 1 & 1 & 1 & 1 & 1 & 1 & 1 \\
\hline polB* & 1 & 1 & 1 & 1 & 1 & 1 & 1 & 1 \\
\hline umuC* & 1 & 1 & 1 & 1 & 1 & 1 & 1 & 1 \\
\hline sulA & 1 & 1 & 1 & 1 & 1 & 1 & 1 & 1 \\
\hline ssb & 129 & 1 & 1 & 132 & 1 & 1 & 1 & 1 \\
\hline ruvA* & 146 & 137 & 1 & 1 & 1 & 1 & 1 & 1 \\
\hline uvrA* & 163 & 1 & 134 & 152 & 1 & 1 & 1 & 1 \\
\hline uvrB* & 172 & 1 & 134 & 132 & 1 & 1 & 1 & 1 \\
\hline t150 & 172 & 179 & 176 & 173 & 173 & 175 & 178 & 177 \\
\hline $\operatorname{din} F^{*}$ & 216 & 187 & 182 & 182 & 1 & 1 & 1 & 1 \\
\hline uvrD* & 245 & 250 & 259 & 257 & 1 & 1 & 1 & 1 \\
\hline ruvB* & 311 & 213 & 226 & 239 & 644 & 342 & 367 & 394 \\
\hline $\operatorname{din} G^{*}$ & 450 & 322 & 311 & 310 & 168 & 145 & 142 & 145 \\
\hline $\mathrm{rps} \mathrm{U}$ & 1190 & 1779 & 1810 & 2042 & 886 & 1040 & 1021 & 1074 \\
\hline phrB & 1738 & 2659 & 2858 & 1186 & 1460 & 1867 & 2031 & 1139 \\
\hline uvrC & 2534 & 3255 & 1401 & 1666 & 3080 & 3516 & 1937 & 2046 \\
\hline dnaG & 3060 & 1939 & 3119 & 1787 & 2831 & 2726 & 2897 & 1796 \\
\hline rpoD & 3336 & 3493 & 3727 & 1730 & 2622 & 3234 & 2897 & 1865 \\
\hline $\mathrm{ftsK}^{*}$ & 3723 & 3255 & 3583 & 3502 & 169 & 175 & 180 & 180 \\
\hline uvrY & 3723 & 3684 & 3472 & 2903 & 3080 & 3234 & 3173 & 3394 \\
\hline$\#$ tied rank 1 & 128 & 136 & 132 & 131 & 145 & 144 & 141 & 144 \\
\hline
\end{tabular}



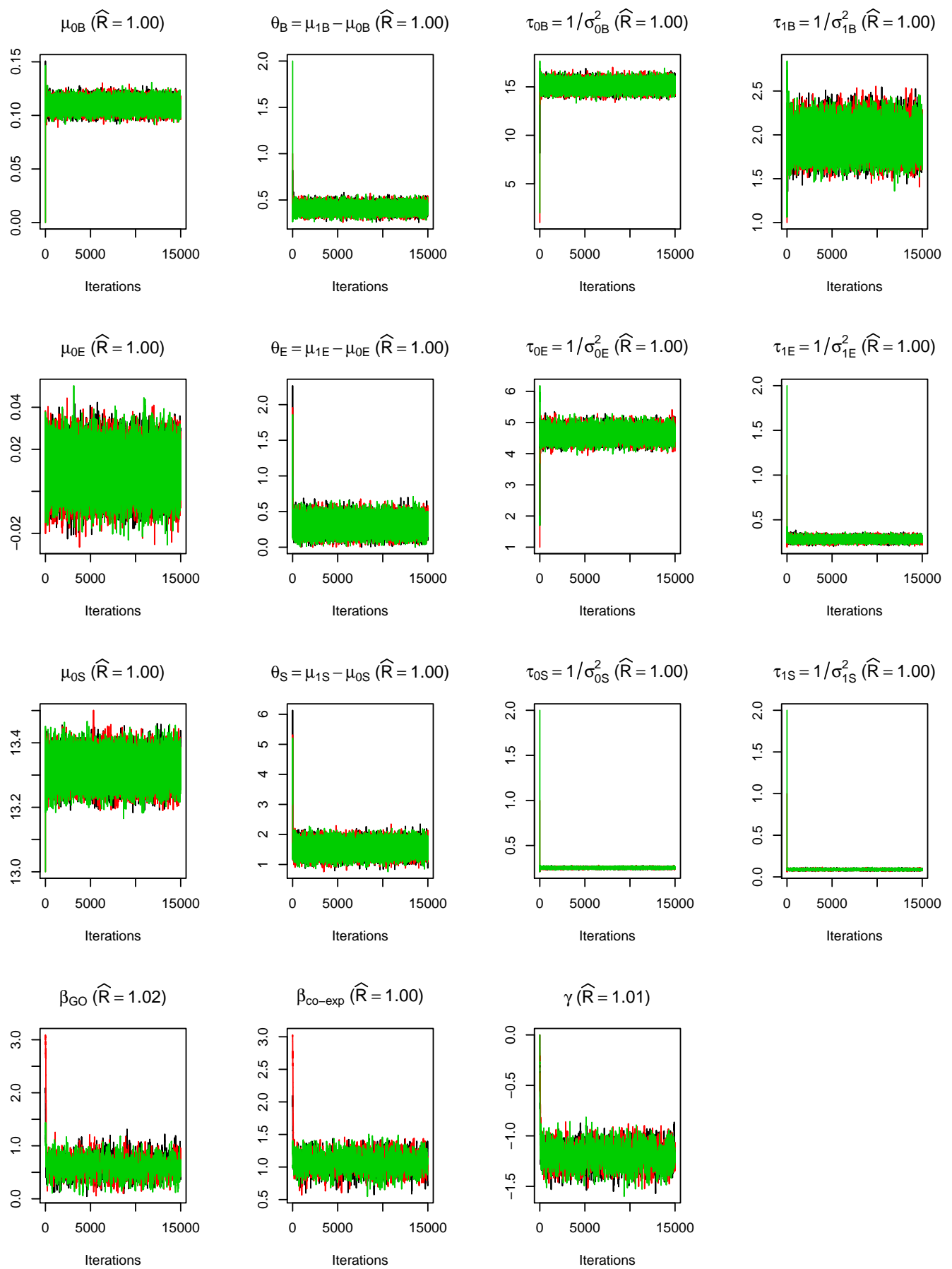

Figure 2: MCMC convergence diagnostics plots. Trace plots of three parallel chains for the mixture component and MRF parameters in the MRF-MJM incorporating both networks. The $\widehat{R}$ statistic of Gelman and Rubin (1992) is a measure of the between- vs within-chain variance ratio, which should converge towards 1 as the multiple chains converge towards each other. $\widehat{R}$ values close to 1 suggest good convergence. 